\title{
HUBUNGAN KADAR HIGH DENSITY LIPOPROTEIN (HDL) DENGAN KEJADIAN HIPERTENSI
}

\author{
Muh. Syahril Rafsanjani ${ }^{1}$, Asriati $^{2}$, Andi Noor Kholidha ${ }^{3}$, La Ode Alifariki ${ }^{4}$ \\ ${ }_{1,2,3,4}$ Fakultas Kedokteran Universitas Halu Oleo, Sulawesi Tenggara, Indonesia \\ *Email: safranjani@yahoo..co.id
}

\begin{abstract}
ABSTRAK
Penelitian ini bertujuan untuk mengetahui korelasi antara kadar HDL sebagai faktor risiko hipertensi. Penelitian ini menggunakan desain analitik observasional dengan pendekatan cross sectional. Variabel bebas adalah kadar kolesterol total dan variabel terikat adalah hipertensi. Penelitian ini berlokasi di Desa Selabangga, Kabupaten Moramo dengan jumlah sampel sebanyak 57 sampel berdasarkan kriteria inklusi dan eksklusi yang dipilih dengan metode purposive sampling. Data ini diperoleh dengan menggunakan instrumen pengukuran tingkat HDL (lipid Pro) dan alat pengukur tekanan darah (aneroid sphygmomanometer). Hasil data diolah dengan uji statistik Chi Square dan Prevalence Odds Ratio (POR). Hasil penelitian HDL pada hipertensi menemukan bahwa dari 57 responden, 34 responden $(56,9 \%)$ adalah hipertensi dan 25 responden $(43,9 \%)$ adalah hipertensi dengan tingkat HDL berisiko. Berdasarkan uji statistik Chi-square, ditemukan bahwa antara tingkat HDL dan hipertensi menunjukkan nilai p $0,000<\alpha(0,05)$. Sementara, nilai POR dari variabel HDL adalah $10.000 \mathrm{CI} 95 \%$ 2.865-34.899. Kesimpulan dari penelitian ini adalah tingkat HDL berkorelasi sebagai faktor risiko untuk kejadian hipertensi.
\end{abstract}

Kata kunci: Hipertensi; Kadar High Density Lipoprotein (HDL); Desa Selabangga

\begin{abstract}
Eventyally this study aims to determine the correlation between HDL levels as a risk factor of hypertension. This research used observational analytic design with cross sectional approach. The independent variable was total cholesterol levels and the dependent variable was hypertension. The research was located in Selabangga Village, Moramo District with the total sample of 57 samples based on the inclusion and exclusion criteria selected by the purposive sampling method. These data were obtained by using a measurement instrument of HDL level (lipids Pro) and blood pressure measurement devices (aneroid sphygmomanometer). The result of data was processed by Chi Square statistic test and Prevalence Odds Ratio (POR). The results of HDL research on hypertension found that from the 57 respondents, 34 respondents $(56,9 \%)$ were hypertension and 25 respondents $(43,9 \%)$ were hypertension whit HDL level at risk. Based on Chi-square statistical test, it was found that between HDL level and hypertension showed $p$ value of $0.000<\alpha(0,05)$. While, the POR value of the HDL variable was 10,000 CI $95 \%$ 2,865-34,899. The conclusion of this study was the HDL level correlated as a risk factor for hypertension incidence.
\end{abstract}

Keywords: Hypertension, High Density Lipoprotein (HDL) levels, Selabangga Village 


\section{PENDAHULUAN}

Salah satu jenis penyakit tidak menular yang sering berasosiasi dengan penyakit tidak menular lainnya kemudian menimbulkan komplikasi pada berbagai organ tubuh adalah hipertensi. Penyakit hipertensi jika tidak mendapatkan penanganan yang baik dapat berdampak pada munculnya penyakit jantung koroner, stroke dan penyakit ginjal ${ }^{(1),(2) .}$

Angka kesakitan dan kematian akibat penyakit hipertensi sangat tinggi terutama pada penyakit hipertensi dengan komplikasi stroke dan penyakit jantung yang menjadi penyebab setengah dari kematian diakibatkan stroke dan penyakit jantung diakibatkan karena penyakit hipertensi. Di wilayah Asia Tenggara diperkirakan 1,5 juta jiwa pertahun dan 9,4 juta kematian di seluruh dunia terjadi akibat komplikasi penyakit hipertensi ${ }^{(3)}$.

World Health Organization (WHO) merilis data tentang proporsi angka kejadian hipertensi, dimana kecenderungan penyakit ini terjadi lebih tinggi pada Negara berkembang seperti Indonesia, dibandingkan Negara maju. Angka prevalensi diperkirakan akan terus meningkat dari tahun ke tahun, di seluruh dunia sekitar 972 juta orang atau 26,4\% penduduk dunia menderita hipertensi, dan akan meningkat menjadi $29,2 \%$ di tahun $2025^{(3)}$.

Hasil survey membuktikan bahwa kejadian hipertensi yang diakibatkan oleh penyakit seperti gangguan ginjal, hormon dan sebagainya lebih tinggi angka prevalensinya dibandingkan hipertensi primer atau esensial yang penyebab seperti faktor usia dan jenis kelamin dengan perbandingan 9:1 ${ }^{(4)}$.

Seorang pasien dikatakan menderita hipertensi atau tekanan darah tinggi jika pada saat pemeriksaan tekanan darah menunjukkan ekanan darah sistolik lebih dari atau sama dengan $140 \mathrm{mmHg}$ dan tekanan darah diastolik lebih dari atau sama dengan $90 \mathrm{mmHg}$. Hal ini diperoleh dari dua kali hasil pengukuran dimana kondisi pasien dalam keadaan tenang bebas dari aktivitas fisik. Mekanisme terjadinya kerusakan pada ginjal (gagal ginjal), jantung (penyakit jantung koroner) dan otak (menyebabkan stroke) akibat dari peningkatan tekanan darah dalam jangka waktu lama dan tidak dideteksi secara dini.

Kurangnya pemahaman masyarakat memberikan kontribusi besar terhadap tingginya angka prevalensi hipertensi. Oleh karena itu, seakan hal ini menjadi suatu pekerjaan rumah bagi semua pihak, bukan hanya pemerintah akan tetapi sector swasta juga harus ikut berkontribusi untuk menurunkan angka prevalensi kejadian hipertensi ini ${ }^{(5)}$. Penyebab kejadian hipertensi adalah multi faktor. Hal ini sesuai dengan teori penyebab gangguan kesehatan bahwa selain faktor individu, penyebab penyakit dapat diakibatkan oleh perilaku, ketersediaan sarana kesehatan dan lingkungan. Pada variabel individu terdapat umur, ras dan jenis kelamin, sedangkan faktor perilaku seperti konsumsi garam berlebih, aktivitas fisik, tingginya kadar lipid atau kolesterol, konsumsi rendah serat, kebiasaan merokok, obesitas dan sebagainya ${ }^{(6),(7)}$

Peningkatan kadar profil lipid darah akan berdampak pada risiko terjadinya aterosklerosis atau kerusakan pada endotel pembuluh darah, terutama bagi pasien yang berusia di atas 40 tahun. Pola konsumsi yang tidak sehat seperti mengkonsumsi makanan tinggi kolesterol menjadi salah satu pencetus meningkatnya tekanan darah. Bahkan pada pasien yang memiliki kadar kolesterol $260 \mathrm{mg} / \mathrm{dl}$ akan meningkatkan peluang aterosklerosis sampai 5 kali lipat ${ }^{(8)}$.

Salah satu jenis profil lipid yang bersifat positif bagi pasien adalah High Density Lipoprotein (HDL), yang bekerja mengangkut kolesterol jahat dari endotel pembuluh darah sehingga tidak terjadi akumulasi kolesterol dalam endotel pembuluh darah kemudian diangkut ke hepar dan kemudian dibuang melalui saluran pencernaan ${ }^{(9)}$. Aterosklerosis terjadi akibat terakumulasinya kolesterol jahat pada endotel pembuluh darah, sehingga dengan keberadaan kolesterol HDL akan membersihkan pembuluh darah dari kolesterol jahat. Fungsi dari HDL selain mengangkut kolesterol jahat juga menyebabkan pembuluh darah bisa berdilatasi karena produksi NO yang meningkat (10)

Peningkatan tekanan darah atau hipertensi seringkali disertai adanya perubahan-perubahan 
metabolik seperti gangguan toleransi glukosa, hiperinsulinemia, obesitas, perubahan humoral seperti peningkatan aktivitas renin plasma, katekolamin, aldosteron dan diikuti perubahan hemodinamik seperti hipertropi ventrikel kiri, dan gangguan fungsi diastolik. Salah satu faktor yang berpengaruh adalah kadar HDL yang rendah.

Dari suatu hasil penelitian deskriptif pada tahun 2012 di Yogyakarta menggunakan subjek 25 orang hipertensi dan 25 orang normal, didapatkan rerata profil HDL individu pada hipertensi rendah, dan perbedaan signifikan antara profil HDL individu hipertensi dengan normal ${ }^{(11)}$.

Jumlah kasus hipertensi di Sulawesi Tenggara masih tergolong sangat tinggi yaitu sebanyak 18.054 kasus dan menduduki peringkat pertama penyakit terbanyak ${ }^{(12)}$.

Kasus hipertensi di wilayah Konawe Selatan terus mengalami peningkatan, pada tahun 2015 tercatat 2.328 dan pada tahun 2016 tercatat 4.356 kasus. Penduduk Desa Selabangga dalah 407 jiwa. Teridiri dari lakilaki 211 jiwa dan prempuan 196 jiwa. Rata-rata mata pencaharian masyarakat Desa Sebabangga adalah petani, buruh, dan tukang. Jumlah Kepala Keluarga sebanyak $91 \mathrm{KK}$, budaya masyarakat Desa Selabangga sangat kental dengan budaya Tolaki. Islam sebagai mayoritas dianut oleh masyarakat dalam menjalankannya ibadah kental dengan tradisi Tolaki yang di selingi dalam Bahasa tolaki. Tradisi budaya tolaki sendiri berkembang dan banyak dipengaruhi ritualritual angama atau kepercayaan masyarakat

\section{METODE}

Penelitian ini menggunakan metode penelitian analitik observasional dengan desain penelitian cross sectional. Penelitian ini dilakukan di Desa Selabangga Kecamatan Moramo Kabupaten Konawe Selatan pada bulan November sampai Desember tahun 2018. Teknik pengambilan sampel menggunakan metode purposive sampling dengan sampel sebanyak 57 sampel. Pengumpulan data menggunakan data primer dan data sekunder. Data primer diperoleh dari Data primer didapatkan dengan melakukan pengukuran secara langsung terhadap masyarakat yang memenuhi kriteria untuk dijadikan sampel. Sedangkan data sekunder diperoleh dari laporan dan catatan studi pendahuluan yang dilakukan di desa tersebut.

\section{HASIL}

Berdasarkan tabel 1. menunjukkan bahwa dari jumlah sampel dalam penelitian ini terdapat responden yang hipertensi sebanyak 34 orang $(59,6 \%)$ sedangkan responden yang tidak hipertensi sebanyak 23 orang (40,4\%). Hasil data pada Tabel 2. menunjukkan bahwa dari jumlah sampel dalam penelitian ini usia responden $\leq 46$ tahun sebanyak 38 responden $(63,0 \%)$ dan responden yang berusia $>46$ tahun sebanyak 29 responden $(33,3 \%)$.

Berdasarkan kadar HDL usia $\leq 46$ tahun yang memiliki kadar HDL yang berisiko sebanyak 17 orang $(29,8 \%)$ dan usia $>46$ tahun yang memiliki kadar HDL yang berisiko sebanyak 13 orang $(22,8 \%)$. Distribusi berdasarkan jenis kelamin responden laki-laki sebanyak 31 orang $(54,4 \%)$ dan perempuan sebanyak 26 orang $(45,6 \%)$. Berdasarkan kadar HDL jenis kelamin laki-laki yang memiliki kadar HDL yang berisiko sebanyak 20 orang $(31,5 \%)$ dan jenis kelamin perempuan yang memiliki kadar HDL yang berisiko sebanyak 10 orang $(17,5 \%)$.

Distribusi berdasarkan konsumsi alkohol didapatkan hasil tidak menkonsumsi alkohol sebanyak 48 orang $(84,2 \%)$ sedangkan responden yang menkonsumsi alkohol sebanyak 9 orang (15,8\%). Berdasarkan kadar HDL responden yang mengkonsumsi alkohol dan memiliki kadar HDL yang berisiko sebanyak 9 orang $(15,8 \%)$ dan responden yang tidak mengkonsumsi alkohol dan memiliki kadar HDL yang berisiko sebanyak 0 orang $(0 \%)$. Hasil data pada Tabel 3. menunjukkan bahwa dari jumlah sampel dalam penelitian ini usia responden $\leq 46$ tahun sebanyak 38 responden $(63,3 \%)$ dan responden yang berusia $>46$ tahun sebanyak 19 responden $(33,3 \%)$.

Berdasarkan kejadian hipertensinya usia $\leq 46$ tahun yang mengalami hipertensi sebanyak 18 orang $(31,6 \%)$ dan usia $>46$ tahun yang 
mengalami hipertensi sebanyak 16 orang $(28,1 \%)$. Berdasarkan jenis kelamin lakilaki sebanyak 31 orang $(54,4 \%)$ sedangkan perempuan sebanyak 26 orang $(45,6 \%)$. Berdasarkan kejadian hipertensinya, jenis kelamin laki-laki yang mengalami hipertensi sebanyak 22 orang $(18,5 \%)$, sedangkan jenis kelamin perempuan yang mengalami hipertensi adalah sebanyak 12 orang (15,5\%). Berdasarkan konsumsi alkohol, responden yang tidak menkonsumsi alkohol sebanyak 48 orang $(84,2)$ sedangkan responden yang menkonsumsi alkohol sebanyak 9 orang $(15,8 \%)$.

Berdasarkan kejadian hipertensinya, responden tidak mengkonsumsi alkohol dan mengalami hipertensi adalah sebanyak 27 orang $(47,4 \%)$ responden yang mengkonsumsi alkohol dan mengalami hipertensi adalah sebanyak 7 orang (12,3\%). Tabel 4. menunjukkan bahwa dari jumlah sampel dalam penelitian ini terdapat responden yang kadar HDL berisiko sebanyak 30 orang $(52,6 \%)$ sedangkan yang kadar HDL yang tidak berisiko sebanyak 27 orang $(47,4 \%)$. Berdasarkan kejadian hipertensinya, responden yang memiliki kadar HDL berisiko dan mengalami hipertensi adalah sebanyak 25 orang $(43,9 \%)$, sedangkan responden yang memiliki kadar HDL yang tidak berisiko dan mengalami hipertensi adalah sebanyak 9 orang $(15,8 \%)$. 
Tabel 1. Distribusi Responden Berdasarkan Tekanan Darah

\begin{tabular}{lcc}
\hline \multicolumn{1}{c}{ Tekanan Darah } & Jumlah (n) & Persentase (\%) \\
\hline & 34 & \\
Hipertensi & 23 & 59,6 \\
Tidak Hipertensi & & 40,4 \\
\hline
\end{tabular}

Tabel 2. Distribusi responden berdasarkan usia, jenis kelamin, dan konsumsi alkohol dengan HDL

\begin{tabular}{cccccccc}
\hline \multirow{2}{*}{ Karakteristik Responden } & \multicolumn{2}{c}{ Distribusi } & \multicolumn{4}{c}{ HDL } \\
\cline { 3 - 8 } & & & \multicolumn{2}{c}{ Berisiko } & \multicolumn{2}{c}{ Tidak Berisiko } \\
\cline { 3 - 7 } & & $\mathrm{n}$ & $\%$ & $\mathrm{n}$ & $\%$ & $\mathrm{n}$ & $\%$ \\
\hline \multirow{2}{*}{ Usia } & $\leq 46$ Tahun & 38 & 66,7 & 17 & 29,8 & 21 & 36,8 \\
& $>46$ Tahun & 19 & 33,3 & 13 & 22,8 & 6 & 10,5 \\
\multirow{2}{*}{ Kenis Kelamin } & Laki-Laki & 31 & 54,4 & 20 & 31,5 & 11 & 19,3 \\
& Perempuan & 26 & 45,6 & 10 & 17,5 & 16 & 28,1 \\
Alkohol & Ya & 9 & 15,8 & 9 & 15,8 & 0 & 0 \\
& Tidak & 48 & 84,2 & 21 & 36,8 & 27 & 47,4 \\
\hline
\end{tabular}

Tabel 3. Distribusi responden berdasarkan usia, jenis kelamin, dan konsumsi alkohol dengan hipertensi

\begin{tabular}{cccccccc}
\hline \multirow{2}{*}{ Karakteristik Responden } & \multicolumn{2}{c}{ Distribusi } & \multicolumn{4}{c}{ Hipertensi } \\
\cline { 3 - 7 } & & & & \multicolumn{2}{c}{ Hipertensi } & \multicolumn{2}{c}{ Tidak Hipertensi } \\
\cline { 3 - 7 } & & $\mathrm{n}$ & $\%$ & $\mathrm{~N}$ & $\%$ & $\mathrm{n}$ & $\%$ \\
\hline \multirow{2}{*}{ Usia } & $\leq 46$ Tahun & 38 & 66,7 & 18 & 31,6 & 20 & 35,1 \\
& $>46$ Tahun & 19 & 33,3 & 16 & 28,1 & 3 & 5,3 \\
\multirow{2}{*}{ Jenis Kelamin } & Laki-Laki & 31 & 54,4 & 22 & 18,5 & 9 & 12,5 \\
& Perempuan & 26 & 45,6 & 12 & 15,5 & 14 & 10,5 \\
Alkonsumsi & Ya & 9 & 15,8 & 7 & 12,3 & 2 & 3,5 \\
& Tidak & 48 & 84,2 & 27 & 47,4 & 21 & 36,8 \\
\hline
\end{tabular}

Tabel 4. Analisis Hubungan Antara Kadar HDL dan Kejadian Hipertensi di Desa Selabangga Kecamatan Moramo Konawe Selatan

\section{Hipertensi}

\begin{tabular}{|c|c|c|c|c|c|c|c|c|}
\hline \multirow{2}{*}{ Kadar HDL } & \multicolumn{4}{|c|}{ Tidak } & \multirow[t]{2}{*}{ Pvalue } & \multirow[t]{2}{*}{ POR } & \multicolumn{2}{|c|}{ CI 95\% } \\
\hline & $\mathbf{n}$ & $\%$ & $\mathbf{n}$ & $\%$ & & & Lower & Upper \\
\hline Berisiko & 25 & 43,9 & 5 & 8,8 & & & & \\
\hline Tidak berisiko & 9 & 15,7 & 18 & 31,6 & 0,000 & 10,000 & 2,865 & 34,899 \\
\hline
\end{tabular}


Berdasarkan pada Tabel 4. dari 57 responden, jumlah responden yang mengalami hipertensi sebanyak 34 responden. Dari 34 responden tersebut, 25 responden $(43,9 \%)$ memiliki kadar HDL berisiko dan 9 responden $(15,8 \%)$ memiliki kadar HDL tidak berisiko. Sedangkan jumlah responden yang tidak mengalami hipertensi adalah 23 responden (40,4\%). Dari 23 responden tersebut, 5 responden $(8,8 \%)$ memiliki kadar HDL berisiko dan 18 responden $(31,6 \%)$ memiliki kadar HDL tidak berisiko.

\section{PEMBAHASAN}

Berdasarkan hasil analisis dengan uji chisquare diperoleh nilai $p$ yang bermakna yaitu $p$ $=0,000$ yang artinya hipotesis diterima, hal ini menunjukkan bahwa terdapat hubungan antara kadar HDL dengan kejadian hipertensi di Desa Selabangga Kecamatan Moramo Konawe Selatan dengan tingkat keeratan hubungan sedang. Selain itu, hasil uji statistik juga menunjukkan nilai POR (Prevalence odds ratio) sebesar 10,000 dengan tingkat kepercayaan 95\% nilai POR berada pada interval 2,865-34,899 menunjukkan bahwa kadar HDL merupakan faktor risiko untuk terjadinya hipertensi pada masyarakat di Desa Selabangga Kecamatan Moramo Konawe Selatan Berdasarkan analisis bivariat, didapatkan adanya hubungan antara HDL dengan kejadian hipertensi pada masyarakat di Desa Selabangga Kecamatan Moramo Konawe Selatan dengan nilai $p$-value adalah $0,000(\mathrm{p}<0,005)$ dan nilai $\mathrm{POR}=10,000$ $(\mathrm{CI} 95 \%=2,865-34,899)$. Hal ini berarti kadar HDL memiliki hubungan bermakna dengan kejadian hipertensi dengan tingkat keeratan sedang dan orang yang memiliki kadar HDL yang rendah 10 kali lebih berisiko mengalami hipertensi dibandingkan dengan orang yang memiliki kadar HDL normal.

Sejalan dengan riset Rahmat Feryadi ${ }^{(8)}$ menemukan terjadinya aterosklerosis, dimulai dari kolesterol tinggi, dengan mekanisme terbentuknya gel busa pada endotel pembuluh darah. Dengan tingginya kadar HDL menyebabkan kolesterol yang telah menempel pada pembuluh darah kemudian dievakuasi ke organ hati kemudian dikeluarkan dari tubuh melalui gastrointestinal.

Sejalan dengan penelitian Soyama dan kawan-kawan di Kota Oyabe, Jepang terhadap 132 orang laki-laki dan wanita yang mengalami stroke, diperoleh data penurunan kadar kolesterol HDL kurang dari $40 \mathrm{mg} / \mathrm{dL}$ hampir seimbang antara laki-laki dan perempuan, sedangkan penderita dengan kadar kolesterol HDL diatas 40 didapatkan sebanyak 13 orang laki-laki dan sebanyak 29 orang wanita. Penelitian yang diikuti selama 10 tahun pada laki- laki dan wanita Jepang ini disimpulkan memiliki hubungan signifikan dan independen terhadap kejadian hipertensi dan stroke, jika kadar kolesterol HDL pasien rendah.

Berdasarkan tabel bivariat dari 57 responden, sebanyak 25 responden (43,9\%) masuk ke dalam kelompok hipertensi dan berisiko. Berdasarkan fakta yang ditemukan di lapangan, sebagian besar warga Desa Selabangga mengkonsumsi gorengan menggunakan minyak eceran yang digunakan berkali-kali. Dimana pada suhu tertentu minyak goreng ketika dipanaskan di atas suhu $100^{\circ} \mathrm{C}$ akan membentuk asam lemak jenuh Trans yang menekan kadar HDL dan meningkatkan kolesterol LDL ${ }^{(13)}$.

Penggunaan minyak berkali-kali, akan menghasilkan senyawa asam lemak bebas berantai panjang yang cenderung tidak terestifikasi. Semakin banyak mengkonsumsi senyawa ini, maka akan semakin meningkatkan kadar kolesterol $^{(14)}$.

Terbentuknya membran sel dan lapisan eksterna lipoprotein plasma berasal dari kolesterol. Kolesterol yang meningkat, akan menyebabkan perubahan terhadap pembuluh darah. Perubahan awal didahului dengan lesi aterosklerosis berada pada sel endotel. Umumnya cedera endotel kronik mengakibatkan disfungsi endotel yang tidak memberikan gejala. Cedera endotel akan menurunkan produksi nitrit oksida (NO) dan menginduksi sel endotel yang bersifat prokoagulan dan membentuk substansi vasoaktif seperti sitokin dan faktor 
pertumbuhan. Proses radang merangsang migrasi dan proliferasi sel otot polos pembuluh darah membentuk bercak ateroma. Bila proses radang tidak efektif untuk melawan agen penyerang maka respon radang akan berlangsung terus menerus sehingga akan direkrut lebih banyak sel-sel makrofag, limfosit, dan trombosit, yang bermigrasi dari pembuluh darah masuk kedalam lesi aterosklerosis. Plak aterosklerosis yang semakin besar akan membuat lumen pembuluh darah sehingga suplai oksigen dari darah kejaringan berkurang. Suplai oksigen yang menurun ini, akan menyebabkan tubuh melakukan kompensasi dengan semakin meningkatkan fungsi jantung. Aktivitas fungsi jantung yang meningkat dalam keadaan lumen pembuluh darah yang menyempit inilah yang bermanifestasi klinis sebagai hipertensi ${ }^{(15)}$.

HDL membantu menahan proses aterosklerosis, dibentuk pada organ hati dan usus sebelum masuk ke pembuluh darah. Setelah disekresikan ke dalam darah, HDL mengalami perubahan akibat berinteraksi dengan kilomikron dan Very Low Density Lipoprotein (VLDL). Dengan kedua lipid ini, HDL saling bertukar lipid dan lemak. HDL juga menyerap kolesterol dari permukaan sel dan dari lipoprotein lain dan juga mengubahnya menjadi ester kolesterol. Ester kolesterol ini akhirnya dikembalikan ke hati, sehingga HDL dikatakan berperan dalam transpor kolesterol terbalik (reverse cholesterol transport) ${ }^{(16}$ ).

Responden yang kadar HDL tidak berisiko tetapi mengalami hipertensi yakni sebanyak 9 responden (15,8\%). Beberapa alasan yang menyebabkan hipertensi selain kadar kolesterol adalah genetik, usia, obesitas, jenis kelamin, stress, kurang aktivitas fisik, pola asupan garam dalam diet ${ }^{(17)}$. Pada saat melakukan penelitian, peneliti menemukan responden yang mengalami obesitas, memiliki keturunan hipertensi, dan mengkonsumsi garam lebih dari 1 sendok teh perhari. Sehingga frekuensi tersebut kemungkinan diakibatkan karena faktor-faktor tersebut.

Berdasarkan tabel bivariat, ditemukan responden yang memiliki kadar HDL berisiko sebanyak 5 orang $(8,8 \%)$ tetapi tidak hipertensi. Berdasarkan penelitian yang dilakukan oleh
Lingga (18), menyatakan bahwa pada hakekatnya penderita hipertensi tidak selamanya memiliki kadar kolesterol tinggi dan juga sebaliknya bahwa tidak semua pasien yang tidak menderita hipertensi tidak memiliki kadar kolesterol tinggi, artinya bahwa banyak faktor lain kemudian berasosiasi dengan kolesterol untuk meningkatkan tekanan darah. Pasien yang paling berisiko memiliki kadar kolesterol tinggi adalah mereka yang tidak dapat mengontrol pola makan berisiko. Menurutnya juga, seseorang yang mengalami hiperkolesterolemia membutuhkan waktu untuk menjadi hipertensi melalui proses pembentukan plak aterosklerosis. Sehingga peneliti menduga, kadar kolesterol dalam darah tinggi namun waktu menderitanya belum lama. Sehingga, belum terbentuk plak aterosklerosis.

Pada penelitian ini diperoleh data bahwa ada 5 responden yang memiliki kadar HDL berisiko akan tetapi tidak menderita hipertensi. Hal ini berhubungan dengan faktor lain seperti tingkat aktivitas fisik yang dilakukan oleh responden tersebut secara teratur, sehingga kadar kolesterol atau LDL dapat terkontrol, sehingga produksi nitrit oxide tetap stabil dan bekerja mempertahankan fungsi endotel secara maksimal.

\section{SIMPULAN}

Terdapat hubungan antara kadar High Density Lipoprotein (HDL) dengan kejadian hipertensi di Desa Selabangga Kecamatan Moramo Kabupaten Konawe Selatan. Bagi peneliti selanjutnya perlu dilakukan penelitian lebih lanjut dengan menggunakan jenis pendekatan case control atau cohort, pengambilan sampel melalui intravena dan membuat kuesioner terpimpin, untuk dapat melacak informasi data yang didapatkan

\section{DAFTAR PUSTAKA}

1. Gallieni M, Aiello A, Tucci B, Sala V, Brahmochary Mandal SK, Doneda A, et al. The burden of hypertension and kidney disease in northeast India: The institute for indian mother and child noncommunicable diseases project. Sci 
World J. 2014;2014.

2. La Ode Alifariki SK. Epidemiologi Hipertensi: Sebuah Tinjauan Berbasis Riset [Internet]. Penerbit LeutikaPrio; 2019. Available from: https://scholar.google.com/scholar?hl=i $\mathrm{d} \&$ as_sdt $=0 \% 2 \mathrm{C} 5 \& \mathrm{q}$

3. World Health Organization (WHO). World Health Statistics of Hypertension [Internet]. Geneva, Switzerland: d; 2015. Available from: https://www.who.int/news-room/factsheets/detail/hypertension

4. Anggara, F.H.D., Prayitno N. FaktorFaktor Yang Berhubungan Dengan Tekanan Darah Di Puskesmas Telaga Murni, Cikarang Barat Tahun 2012. J Ilm Kesehat. 2013;5(1).

5. Destiani, D.P., Rina, S., Eli, H., Ellin, F., Syahrul N. Evaluasi Penggunaan Obat Antihipertensi pada Pasien Rawat Jalan di Fasilitas Kesehatan Rawat Jalan pada Tahun 2015 dengan Metode ATC/DDD. Farmaka. 2016;14(2):2.

6. Magfirah AL. PENGARUH TERAPI BERKEBUN TERHADAP PERUBAHAN TEKANAN DARAH PADA LANSIA DENGAN HIPERTENSI DI PANTI SOSIAL TRESNA WERDHA MINAULA KENDARI. J Islam Nurs. 2018;3(2):715.

7. Alifariki LO. Analisis Faktor Determinan Proksi Kejadian Hipertensi di Poliklinik Interna BLUD RSU Provinsi Sulawesi Tenggara. Medula. 2015;3(1):214-23.

8. Feryadi, R., Sulastri, D., Kadri H. Hubungan Kadar Profil Lipid dengan Kejadian Hipertensi pada Masyarakat Etnik Minangkabau di Kota Padang Tahun 2012. J Kesehat Andalas. 2014;3(2):1-2.

9. Kuang H, Yang F, Zhang Y, Wang T, Chen G. The Impact of Egg Nutrient Composition and Its Consumption on Cholesterol Homeostasis. 2018;2018.

10. Pratiwi N. Hubungan High Density Lipoprotein dengan Penurunan Fungsi Kognitif pada Wanita Post Menopause.
Universitas Muhammadiyah Surakarta; 2010.

11. Andini, J., Nugroho P. Hubungan Kadar High Density Lipoprotein (HDL) terhadap kendali tekanan darah pada pasien hipertensi poliklinik penyakit dalam RSUPN DR.Cipto Mangunkusumo Jakarta. J FK UI. 2013;5(2):2.

12. Dinkes Propinsi Sultra. Profil Kesehatan Propinsi Sulawesi Tenggara. Kendari; 2018.

13. Sartika R. Pengaruh Suhu dan Lama Proses Menggoreng (Deep Frying) terhadap Pembentukan Asam Lemak Trans. Makara, Sains. 2009;13(1):23-8.

14. Kataren S. Pengantar Teknologi Minyak dan Lemak Pangan. Jakarta: UI Press; 2005.

15. Lintong P. Perkembangan Konsep Patogenesis Aterosklerosis. J Biomedik. 2009;1(1).

16. Murray R.K, Granner D.K RV. Biokimia Klinik Edisi. Jakarta: EGC; 2009.

17. Nuraini. Risk Faktor of Hypertension. J Major. 2015;4(5):10-9.

18. L L. Bebas Hipertensi Tanpa Obat. Jakarta: Agro Media Pustaka; 2012. 